\title{
Joaquín Llorca
}

Universidad Icesi, Colombia

jllorcaı@yahoo.com

\section{Cine, ciudad y arquitectura, apuntes metodológicos. El caso de El grupo de Cali ${ }^{\mathrm{I}}$}

\author{
Film, City, and Architecture: Methodological Notes: the Case \\ of The Cali Group
}

Cinema, cidade e arquitetura, pontos metodológicos. O caso do grupo de Cali

Artículo de reflexión recibido el 03/01/12 y aprobado el 07/05/12

I El presente artículo es producto de la investigación "Cali proyectada. Ciudad e imagen en el cine de Caicedo, Mayolo y Ospina”, adelantada durante el 201 en el Departamento de Humanidades de la Universidad Icesi de Cali. Agradezco a Alejandra Erazo, estudiante de antropología quien fue fundamental en la recolección y clasificación del material. 



\title{
Resumen
}

Indagando en los referentes culturales que las películas sugieren en su puesta en escena, el presente artículo pretende analizar la representación de la ciudad de Cali en términos de espacio e imagen en los seis filmes de ficción realizados entre 1971 y 1985 por El grupo de Cali integrado por Andrés Caicedo, Carlos Mayolo y Luis Ospina. A la vez hace una revisión de los enfoques con que se estudia la ciudad y la arquitectura a través de la imagen fílmica y propone un acercamiento a su dimensión espacio-temporal por medio del concepto de "cronotopo". Este análisis sirve como base para establecer la tensión entre tradición y modernidad latente en el arte y la ciudad.

Palabras clave: Cine, Ciudad, Arquitectura, Cali, Cronotopo, El grupo de Cali

\begin{abstract}
Delving into the cultural references suggested by the staging of films, this article analyzes the representations of the city of Cali in terms of space and image in the six fiction films created by the Cali Group, consisting of Andrés Caicedo, Carlos Mayolo and Luis Ospina, between 1971 and 1985. It both presents a review of the approach taken to study the city and its architecture through film image and proposes an approach to its space-time dimension through the concept of "chronotope". This analysis will serve as the basis for establishing the tension between tradition and latent modernity within art and the city.
\end{abstract}

Keywords: Film, City, Architecture, Cali, Chronotope, the Cali Group

\section{Resumo}

Indagando os referentes culturais que os filmes sugerem em sua realização, o presente artigo pretende analisar a representaçáo da cidade de Cali, quanto ao espaço e a imagem, nos seis filmes de ficção realizados entre 1971 e 1985 pelo grupo de Cali integrado por Andrés Caicedo, Carlos Mayolo e Luis Ospina. Ao mesmo tempo, faz uma revisão dos enfoques com que se estuda a cidade e a arquitetura através da imagem fílmica, propondo uma aproximação da sua dimensão espaço-temporal por meio do conceito de "cronotopo". Esta analise serve como base para estabelecer a tensão entre tradição e modernidade latente na arte e a cidade.

Palavras-chaves: Cinema, Cidade, Arquitetura, Cali, Cronotopo, O Grupo de Cali 

Es, pues, el tiempo mismo el que se vuelve visible en el montaje de imágenes. Corresponde a cada cual - artista o sabio, pensador o poeta- convertir tal visibilidad en la potencia de ver los tiempos: un recurso para observar la historia, para poder manejar la arqueología y la critica politica, "desmontándola" para imaginar modelos alternativos.

Georges Didi-Huberman

\section{El cine y las ciudades}

Desde que los hermanos Lumière hicieron irrumpir una locomotora en un café de París (I889), la única manera de conocer ciudades no es caminando por ellas. El mundo se asomó a Berlín por el ojo mecánico de Ruttman o a Niza por el de Vigo, pero además del registro documental, el cine optó también por una narrativa, que a través de ficciones, representó la realidad. La construcción espacial que el cine hace de la urbe se traduce en la imagen que llega al espectador, su interpretación hace parte de una memoria que muchas veces es más poderosa que la realidad misma. Nueva York, en palabras de Baudrillard, parece haber sido engendrada por su imagen en la gran pantalla, más que un lugar parece un sueño (Pomerance, 2007 : 3). Por tanto, hemos conocido de otra manera a Nueva York por Manhattan (Allen, 1979), París por Sin aliento (Godard, 1960), Londres por Blow-Up (Antonioni, 1966), Berlín por El cielo sobre Berlín (Wenders, 1987), Viena por El tercer hombre (Reed, 1949), San Francisco por Vértigo (Hitchcock, 1958), Barcelona por El pasajero (Antonioni, 1975), Hong Kong por Chungking Express (Kar-Wai, I994), Ciudad de México por Los olvidados (Buñuel, I950). Luego se hizo conciencia de ello y se comenzó a interpretar el significado de aquellas sombras que además del relato habitaban mundos. Poco a poco las películas se convirtieron en documentos.

Los acercamientos al estudio de la ciudad y la arquitectura a través de la imagen cinematográfica son relativamente nuevos, pero su corpus va creciendo día a día. Uno de los principales antecedentes del fenómeno académico fue el llamado "spatial turn". ${ }^{2}$ Los nuevos teóricos urbanos, que recogían el testigo de las ideas sobre el espacio del sociólogo Henri Lefebvre, juegan un papel fundamental en esta nueva manera de pensar el cine y su relación con lo urbano. "El cine se ha convertido en una categoría del espacio". ${ }^{3}$ Estas palabras de Jordi

2 Nombre con que se ha llamado a la nueva geografía o geografía humana, disciplina que ha dado un giro en el entendimiento del espacio como una entidad abstracta e independiente de su contenido. A finales del siglo XX autores como Lefebvre, Davis, Santos, Soja o Harvey proponen una noción de espacio cuya existencia no es ajena de las relaciones sociales que acoge.

3 Prólogo de Josep Ramoneda, recuperado en: http://www.cccb.org/es/publicacio-la_ciutat_dels_cineastes_la_ciudad_de_los_cineastas-34936 recuperado en diciembre de $201 \mathrm{r}$. 
Batlló se podían leer en el catálogo de la exposición "La ciudad de los cineastas" celebrada en el ссСв de Barcelona en 200I. En ese sentido el espacio puede ser mirado desde lo cultural, desde lo formal y desde lo perceptual.

Desde lo cultural es importante destacar la interdisciplinariedad abarcada por los "estudios culturales" de donde se desprenden los llamados "film studies" y que se ven cruzados por la arquitectura, el urbanismo, la geografía, la sociología y la antropología. Respecto a lo formal los estudios de la ciudad filmada son también una plataforma para el análisis de la arquitectura y lo urbano desde lo estético y lo histórico. En este ámbito hay que resaltar la participación de arquitectos que cada vez más se sirven del cine como instrumento de análisis. Desde lo perceptual podemos citar los trabajos que se ocupan propiamente del lenguaje, el estilo, el significado de la imagen y el texto cinematográfico en relación con la manera de registrar la ciudad. Ésta última categoría dialoga con la mirada formal, pues se ocupa también de aspectos estéticos.

Gran parte de la producción bibliográfica anglosajona (y poco traducida al castellano) tiene un objetivo común en su enfoque: la relación entre los "film studies" y los "urban studies". Valga mencionar el libro Cities and Cinema (2008) de Barbara Mennel, investigadora del cine, que es producto del curso con el mismo nombre impartido en el programa de Humanidades de la Universidad de Maryland, Baltimore County desde 2006. Dicha publicación ejemplifica la tendencia temática de muchas otras publicaciones donde la modernidad, la globalización, los géneros cinematográficos, el género, el postcolonialismo, la distopía y lo étnico son abordados desde el cine y lo urbano. Los libros son en su mayoría compilaciones de ensayos académicos de los "film studies" agrupados por un editor. ${ }^{4}$

Dentro de la bibliografía originada en la arquitectura y el urbanismo se destaca una producción en castellano que, sobre todo en España, viene abordando el tema por medio de publicaciones, ciclos, exposiciones y seminarios. Varias facultades de arquitectura ofrecen cursos y algunos profesionales exploran ciertos tópicos; por ejemplo, la arquitectura moderna vista desde diversas perspectivas (como el cine fantástico de principios de siglo o el uso de edificios icónicos en algunas películas), también el urbanismo moderno y su modelo de ciudad o las ciudades y su arquitectura vistas a través de la cámara. Berlín, Roma, Tokio, Londres, París, todas ellas han tenido papeles principales en muchos films y esto

4 Por ejemplo, Cinema and the City: Film and Urban Societies in a Global Context. Studies in Urban and Social Change, (200I) y Screening the City (2003), editados por Shiel, M. y Fitzmaurice; T., Global cities: Cinema Architecture and Urbanism in the Digital Age (2003), editado por Krause, Linda y Petro, Patrice.; Cities in Transition: The Moving Image and the Modern Metropolis (2008), editado por Webber, A. y Wilson, E.; Noir Urbanisms: Dystopic Images of the Modern City (2010), editado por Prakash, Gyan.; City That Never Sleeps. New York and the Filmic Imagination (2007), editado por Pomerance, Murray. 
sirve como documento de estudio para arquitectos y urbanistas. ${ }^{5}$ Respecto al enfoque estético y formal un ejemplo es el trabajo del arquitecto inglés Graham Cairns quien en La visión espacial del cine. El arquitecto detrás de la cámara (2008) describe la perspectiva arquitectónica de algunas películas, es decir, habla de cómo las particularidades espaciales pueden influir y enfatizar ciertas características del film. Para eso hace una definición del espacio cinematográfico. También acomete una revisión teórica de la revolución óptica protagonizada por el cine y de su influencia en el pensamiento arquitectónico.

Del lado del cine, la mítica revista Cahiers du Cinéma publicó en 2005, a manera de enciclopedia, La ville au cinéma, un volumen dividido en cinco partes que explora la relación ciudad y cine desde la técnica, los géneros, los lugares, las ciudades y los cineastas. Fue editado por Thierry Jousse, antiguo redactor de Cahiers y el filósofo e investigador urbano Thierry Paquot.

Con respecto a las publicaciones sobre el cine y la ciudad en Colombia las referencias son mínimas y su enfoque es más culturalista. En el 2003 se editó con muy poca difusión La ciudad visible: una Bogotá imaginada de Mauricio Cortés Zabala quien se vale de seis largometrajes y tres directores colombianos para explorar las representaciones cinematográficas que se han hecho de Bogotá. Su crítica pone a dialogar los referentes reales e imaginarios de la ciudad desde una perspectiva sociológica. En el 2005, dentro de la colección Comunicación y ciudad, se publica Comunicación, cine colombiano y ciudad del comunicador y periodista Oswaldo Osorio, una recopilación de ensayos y entrevistas que indagan en la realidad del país y su representación fílmica. Juana Suárez publicó en el 2009 Cinembargo Colombia: ensayos críticos sobre cine y cultura, un trabajo que consta de ocho ensayos donde se analiza el papel del cine colombiano en relación con el concepto de cultura y culturas colombianas con algunas referencias urbanas. A partir de algunos largometrajes y documentales establece relación con acontecimientos específicos del país e indaga la forma como el cine colombiano es entendido por el espectador. Hay un capítulo dedicado al cine de El Grupo de Cali.

Este breve recuento permite entender los principales puntos de vista con que se desarrollan las investigaciones y sirve para plantear un acercamiento metodológico. Las imágenes, una vez cargadas de significado, se convierten en

5 El arquitecto José Manuel García Roig imparte cursos sobre cine y arquitectura en la ETSAM de Madrid y ha escrito Mirada en off. Espacio y tiempo en cine y arquitectura (2007) y La arquitectura del cine. Jorge Gorostiza autor de Cine y arquitectura (1990) ha venido realizando, desde la Filmoteca canaria y la Escuela superior de arquitectura, estudios y actividades en tal sentido y hay otras publicaciones como Los espacios de la ficción. La arquitectura del cine (2008) y Paradigmas. El desarrollo de la modernidad arquitectónica visto a través de la historia del cine (2007). 
documentos, la aproximación analítica a estos documentos arroja, a grandes rasgos dos frentes: uno que trata la imagen como objeto de estudio apoyándose en la estética y la semiótica, y otro que la considera una fuente que da cuenta de las formas sociales. La propuesta es establecer un puente entre ambos frentes indagando en su relación a través de lo que Auerbach denomina "referentes" que acaban filtrándose en los procedimientos retóricos. Hay una vida que se revela detrás de las acciones (Quintana, 2003) y bajo esa perspectiva la forma artística y las formas sociales se encuentran en un punto marcado por la dimensión espaciotemporal. Desde el momento en que la ciudad es filmada, aquellos espacios cotidianos dejan de ser individuales para transformarse en signos arrancados por un instante de nuestra vida, ya que en realidad somos inseparables de ellos. No en vano encapsulan un tiempo y un espacio.

\section{Espacio fílmico y poética}

El valor del espacio representado radica en todo lo imaginado que adhiere el espectador, en palabras de Bachelard:

El espacio captado por la imaginación no puede seguir siendo el espacio indiferente entregado a la medida y a la reflexión del geómetra. Es vivido. Y es vivido, no en su positividad, sino con todas las parcialidades de la imaginación. En particular, atrae casi siempre. Concentra ser en el interior de los límites que protegen (Bachelard, 2000: 22).

El espacio cinematográfico es pues un lugar vivo, figurativo, que añade a su aparente tridimensionalidad el tiempo, variable por la cual la cámara explora con nosotros una realidad estética, enriquecida por la historia que nos narra. Es indudable que la poética del cine de ficción aporta, con el relato, una nueva dimensión que supera lo documental. La feliz relación entre espacio y poesía, ese "espíritu del lugar" y ese encuentro con lo habitado a través de una experiencia de desvelamiento, la explica el arquitecto Christian Norgerg-Schulz refiriéndose a un poema de Georg Trakl:

Por tanto el poema concreta las propiedades básicas de la existencia.

'Concretar' significa hacer 'visible' lo general como una situación concreta y localizada. Al hacer esto el poema se mueve en la dirección opuesta al pensamiento científico. Mientras la ciencia parte de lo 'dado', la poesía nos trae de regreso a las cosas concretas, desvelando los significados inherentes a la vida en el mundo [life-world] (NorgergSchulz, I980: I0).

En la representación poética que se hace por medio de la imagen, dice Gombrich (1998) que, aunque una obra se parezca a la realidad, no está constituida 
sólo por ella, el estilo es la huella que da cuenta de la subjetividad del artista. Todos estos elementos se ven forzosamente penetrados, entre otras cosas, por los referentes culturales que en su momento posee el creador. Si Greenaway escoge una mirada que apuesta por el artificio, una mirada estática, simétrica, barroca; para enmarcar sus postales de Roma a través del filtro de Boullé en su película El vientre de un arquitecto (1985), Fellini en Roma (1972) confunde la cámara entre un pelotón de motociclistas para recorrer la Plaza Navona, la Plaza del Pueblo, el Campidoglio, Sant’Angelo, en una mirada más orgánica. Es quizá por esta misma lógica que nos muestra Trastevere caminando, a la altura del peatón.

La ciudad de Cali (Colombia) fue el lugar donde unos jóvenes (posteriormente nombrados como "El grupo de Cali" o "Caliwood") desarrollaron una obra cinematográfica y crítica que se sirvió de la ciudad como inmenso plato para expresar una particular relación con el espacio en el sentido más amplio de la palabra. Este texto pretende indagar la ciudad por ellos proyectada.

\section{El grupo de Cali}

Con esta apelación se ha denominado un movimiento cinematográficoliterario nacido en la ciudad de Cali en los años setenta y que sin manifiesto alguno desarrolló un trabajo colectivo.

La denominación fue necesaria para referirse a la trascendencia que
iban adquiriendo las obras y andanzas de unos pocos buenos amigos
caleños: Andrés Caicedo, Carlos Mayolo y Luis Ospina, inicialmente
[...] Iconoclastas, intelectuales, adolescentes perpetuos, cinéfilos
obsesivos, influidos por el pensamiento y las utopías de la década
del sesenta (la Revolución Cubana, Mayo del 68, 'Sex, Drugs and
Rock \& Roll', viviendo en el ojo de huracán de las convulsiones
contemporáneas, pero perdidos, como todos, en una esquina del
Tercer Mundo. Ospina y Mayolo empiezan a hacer un cine que co-
rresponde a las inquietudes políticas de la época (Hoyos, I994: I69).

La importancia de El grupo de Cali radica en la realización de una obra colectiva que se consolidó con la fundación del Cineclub de Cali (197I) y la revista Ojo al cine (1974). El símbolo de esta reunión fue Ciudad Solar, una vieja casa del fotógrafo Hernando Guerrero sede del Cineclub de Cali, improvisada residencia de artistas y sala de exposiciones. Además de Caicedo, Mayolo y Ospina, acogió a artistas como Óscar Muñoz, Fernell Franco, Édgar Negret, Pedro Alcántara, Feliza Bursztyn, Carlos Rojas, todos ellos reunidos por la curaduría del crítico Miguel González. Aunque nunca se constituyeron oficialmente como un grupo su "disolución" viene a mediados de la década de 1980 cuando Ospina y Mayolo 
abandonaron la ciudad y emprendieron proyectos individuales. Caicedo murió en 1977.

\section{Tiempo y espacio como objetos de estudio}

A través de las seis películas de ficción realizadas entre i971 y I985 e indagando en los referentes culturales que las obras sugieren en su puesta en escena, es posible analizar la representación de la ciudad que hace El grupo de Cali en términos de espacio e imagen. En la narración cinematográfica se llama trama (story) a todos los eventos, explícitos o no, que hacen parte del mundo creado (diégesis) por el autor (Bordwell, Thompson, 2008), en nuestro caso esa diégesis es penetrada por los referentes a que hace mención Auerbach y que dan cuenta de un espacio y tiempo con un significado muy especial para la historia y la memoria de la ciudad.

Para analizar el espacio propuesto por las películas se ha echado mano de forma libre del concepto cronotopo creado por el lingüista ruso Mijail Bajtín quien lo definió como

[...] la conexión esencial de relaciones temporales y espaciales asimiladas artísticamente en la literatura, [... es] la unión de elementos espaciales y temporales en un todo inteligible y concreto. El tiempo se condensa aquí, se comprime, se convierte en visible desde el punto de vista artístico y, el espacio, a su vez se intensifica, penetra el movimiento del tiempo, del argumento y de la historia (Bajtín, 1989: 238).

El término presenta una gran solidez como unidad conceptual y se ofrece sugerente para el análisis de cualquier producto narrativo, por tanto el cine, que se desenvuelve también en una dimensión espacio-temporal, no estaría ajeno a dicha posibilidad. Una película en su configuración formal es una sucesión de fragmentos de tiempo y espacio; en el montaje tradicional los planos establecen entre sí múltiples asociaciones espacio-temporales. Estas micro-asociaciones van construyendo un tiempo y un espacio global imbricados en la historia del film. La importancia del cronotopo radica en que, como unidad organizadora de los relatos, va enlazando la historia, por ende es fundamental en la construcción de significados. También es primordial su papel en la sensibilización que hace del relato, pues define ("concreta” en palabras de Norgerg-Schulz) lugares y momentos de manera profunda. En el cronotopo hay una confluencia entre objeto estético y formas sociales. Su tiempo, en el cronotopo moderno, ${ }^{6}$ es un momento

6 A diferencia del cronotopo de la novela griega donde todo se desarrolla en un universo amplio y mítico donde el espacio concreto no es importante; el cronotopo moderno hace referencia a espacios como "el salón recibidor" en las novelas de Sthendal y Balsac que según Bajtín son lugar de intersección donde se generan los nudos argumentales. 
específico que se llena de referencias culturales y su espacio, además de dichos referentes se plasma formalmente a través de la imagen, el sonido y los diálogos.

\section{Cali proyectada}

Según los historiadores la primera película de la cual se tiene rastro en Colombia fue filmada en Cali, aunque no queda copia alguna, existe la noticia, aparecida en el periódico El Ferrocarril del I6 de junio de I899, recordando una presentación en el Teatro Borrero, donde se proyectaron imágenes de Cali que incluían el puente Ortiz y la iglesia de San Francisco, entre otras. No es casual que las imágenes registraran lugares representativos de la ciudad, poco tiempo después de la aparición del cinematógrafo los cineastas miraron hacia sus ciudades retratando la pulsión de la nueva urbe moderna en todo su esplendor. Nació entonces el documental urbano, género fundamental en la estructuración del cine como máquina de mirar. ${ }^{7}$

Entre 192I y 1922 fue realizado, también en el Valle del Cauca, el primer argumental del país, se trató de María, adaptación de la novela del escritor Jorge Isaacs. El desarrollo del cine en Cali continuó y sobresale, entre los diversos trabajos, otro argumental, Garras de oro de P. P. Jambrina aparece en 1926; posteriormente, en 194I, se filma Flores del Valle de Máximo Calvo considerada el primer argumental sonoro. Sin embargo, es sólo hasta I955 cuando una película de ficción nos muestra la ciudad como protagonista indirecta. La gran obsesión de Guillermo Ribón Alba, "plantea el problema psicológico del provinciano obsesionado por encontrar nuevos y ventajosos horizontes en la ciudad a donde emigra. Contempla el choque de esas dos potencias, la ciudad y el campo" (Arbeláez, 2002).

Con todo, no es hasta los años setenta que la ciudad se ve invadida por un espíritu cinematográfico que debe mucho a la aparición del Cineclub de Cali y de una cultura cinéfila que estimuló a varios jóvenes a hacer cine. Después de realizar varios documentales Carlos Mayolo, en compañía de Andrés Caicedo emprenden la aventura de un argumental, en 1971 trabajan en Angelita y Miguel Ángel, un mediometraje que no se terminó por desacuerdos entre los autores. "Años después, Luis Ospina realizó una edición con el material rodado, más fiel a la idea de Caicedo" (Arbeláez, 2002). El fin de la década del ochenta también marca el fin de una era pues la producción cinematográfica entró en declive.

7 En I888 Louis Le Prince filma la ciudad de Leeds, en I892 desde un tejado los hermanos Sklada Nowsky filman Berlín, algunos años después lo haría Ruttmman con Berlín sinfonía de una ciudad (1927) y en I93I la misma ciudad sería escenario de un argumental: Berlin Alexanderplatz de Piel Jutzi (Barber, 2006 : I7-32). 
Una revisión de la filmografía rodada en Cali deja ver la importancia que las décadas del 1970 y 1980 tienen en la historia cinematográfica de Cali lo cual coincide con transformaciones trascendentales para la ciudad. ${ }^{8}$ La década de los setenta tiene un significado especial, pues la realización de los Juegos Panamericanos en 1971 generó cambios fundamentales en la estructura urbana de la ciudad. Múltiples escenarios deportivos, nuevas vías y barrios enteros fueron construidos modificando la ciudad y su imagen de forma notable. De igual forma, la celebración deportiva congregó mucha gente y puso en la mira internacional la ciudad despertando un espíritu nuevo entre sus habitantes.

Dentro de esta década sobresalieron los tres autores estudiados que trabajando de manera colectiva constituyeron el cimiento de un movimiento llamado El grupo de Cali o Caliwood. La actividad realizada por Caicedo, Mayolo y Ospina, volvió a Cali un centro cinematográfico a partir de una producción crítica acompañada de publicaciones y cineclubes. Aunque la mayor parte de la obra ha sido documental, sobresalen ;Oiga, vea! (Mayolo, 1971) y Cali de película (Mayolo y Ospina, 1972); entre 1971 y 1985 Caliwood realizó seis películas de ficción donde Cali aparece explícitamente como espacio de los relatos.

\section{Las películas}

Angelita y Miguel Ángel (1973-1986).

Dirección: Carlos Mayolo y Andrés Caicedo.

Película inacabada y reconstruida por Ospina, (quien realizó una edición con el material existente) relata la aburrida vida cotidiana de una pareja de adolescentes en un contrapunto entre escenarios interiores y barrios de la ciudad.

Rodillanegra (1976) I5'.

Dirección: Carlos Mayolo.

Ubicada en un barrio muy pobre, narra la historia de un futbolista que luego de sufrir una lesión cae en las drogas y el alcohol. Con una propuesta sobre todo visual, el cortometraje muestra el drama rodeado de colorido y música tropical.

Agarrando pueblo (1977) 28'.

Dirección: Carlos Mayolo, Luis Ospina.

8 La gran obsesión (Guillermo Ribón Alba, 1955), Adorada enemiga (René Cardona Jr.1964), Angelita y Miguel Ángel (Carlos Mayolo,1973), Rodillanegra (Carlos Mayolo,1976), Agarrando pueblo (Carlos Mayolo, Luis Ospina, 1977), Esposos en vacaciones (Gustavo Nieto Roa, 1978), Tacones (Pascual Guerrero, 198I), Pura Sangre (Luis Ospina, 1982), Carne de tu carne (Carlos Mayolo, 1983), Aquel Ig (Carlos Mayolo, 1985), Ella, el chulo y el atarván (Fernando Vélez, 1985), Visa usa (Lisandro Duque, 1985), Valeria (Oscar Campo, 1986), El Rey (Antonio Dorado, 2004), Yo soy otro (Oscar Campo, 2008), Perro come perro (Carlos Moreno, 2008), Dr. Alemán (Tom Schreiber, 2009). 
Falso documental que ironiza sobre las películas que explotaban la miseria tercermundista bajo el formato de "documentales sociales" y se vendían en Europa con mucho éxito. El mediometraje narra las incidencias de unos cineastas que van por las calles intentando extraer de la realidad escenas miserables, dejando ver su oportunismo. Este tipo de cine fue calificado por Mayolo como "porno-miseria".

Pura Sangre (1982) I05'.

Dirección: Luis Ospina.

La enfermedad de un magnate azucarero que necesita sangre para sobrevivir es la metáfora que sirve para poner en juego la economía local de las haciendas de cańa y la explotación que hacen las familias poderosas. Los crímenes para conseguir la sangre se encubren con un evento real: "el monstruo de los mangones", personaje caleño que secuestraba niños y los abandonaba en terrenos baldíos. El vampirismo es la figura que estructura la economía feudal con lo popular en la ciudad de Cali.

Carne de tu carne (1983) 86'.

Dirección: Carlos Mayolo.

Basada en un guión de Caicedo, la película parte de un hecho real y se sitúa en agosto de 1956 cuando una caravana militar explotó destruyendo varios barrios y dejando millares de muertos. La destrucción de arquitectura tradicional es el pretexto para que se liberen secretos de familia guardados en aquellas casas. La notable familia, propietaria de haciendas e ingenios azucareros, muestra el clima de violencia que vive el país a través del incesto y los mitos, todo dentro de las convenciones del llamado "gótico tropical".

Aquel I9 (1985) 25'.

Dirección: Carlos Mayolo.

Localizada en inmediaciones del Barrio Obrero, la película se sitúa en un escenario popular tradicional enmarcado por casas de fachadas coloridas en una suerte de art deco local. Cali cumplía 450 años y el guión da cuenta de ello en un homenaje a la arquitectura, a sus artistas, a la música y al mestizaje. Los protagonistas son dos adolescentes que viven una historia de amor furtiva con final trágico. Un muro que divide sus casas, con un patio compartido simboliza, por un lado, la colectividad espacial de la arquitectura popular y, por otro, el amor imposible.

\section{Espacio-tiempo}


Para evidenciar la relevancia de las relaciones espacio-temporales encapsuladas en el concepto cronotopo anteriormente mencionado, tomaremos como ejemplo la película de Mayolo Carne de tu carne. En los primeros minutos hay una directa situación espacio-temporal, se nos muestra clara y explícitamente la geografía del Valle situando el espacio principal del filme y se nos comunica el tiempo, detallando el lugar con el texto: "Cali, Colombia. 6 de agosto de 1956". La información está sobreimpresionada en una fachada de arquitectura que nos remite a la parte antigua de la ciudad y que entrega aún más información acerca del lugar. Grandes muros blancos (para más señas se están encalando o limpiando como era la costumbre) que predominan sobre los tres vanos, zócalo y cubierta inclinada con teja de barro. El posterior contraplano interior nos descubre una casa tradicional de influencia andalusí con zaguán y patio. Desde el comienzo el patio y sus corredores adyacentes articulan la "explicación" de ese espacio con habitaciones alrededor. En este momento es que la calle se vuelve el escenario y se nos informa un poco más sobre el contexto de la casa, se trata de una calle con casas similares de una sola altura que nos sitúa con más precisión en un entorno tradicional, el centro de la ciudad. La escena posterior tiene lugar en el interior y esta vez el espacio del comedor deja ver la relación con el patio anteriormente descrito. ${ }^{9}$

El visionado de las películas arrojó una clasificación espacial que, apoyándose en el concepto de cronotopo, define cuatro grandes grupos: (I) periferia, (2) ciudad, (3) barrio y (4) interior. La inserción de los relatos en contextos y tiempos tan precisos, sugiere una construcción atada a ese "todo inteligible" que es el cronotopo. Así el barrio se convierte en escenario que da cuenta de unos procesos urbanos reflejados en su arquitectura y en el comportamiento de sus habitantes, la casa de hacienda cañera es un espacio periférico fundamental en la historia socioeconómica de la ciudad, ya que resume la actividad azucarera. Su papel en la arquitectura local será fundamental, pues condensó una sabiduría constructiva que entendía el clima, el contexto y el saber constructivo de forma brillante. También tenemos la ciudad como un gran cronotopo o la casa de patio interior, ya sea colonial (de influencia andalusí) o la popular. En ese sentido mirar las películas a través de los cronotopos definidos entrega unas posibilidades de observación, pues cada unidad espacio-temporal tiene una riqueza histórica en lo urbano y arquitectónico, que como fuente de conocimiento, permite densificar el análisis. La casa de hacienda

9 La recolección de esta información se realizó por medio de unas fichas técnicas (ver anexo) que registran las escenas relevantes para el análisis, marcando el tiempo de las escenas dentro del filme con su duración y haciendo una descripción detallada de la misma en dos aspectos: (I) diégesis: lo que sucede en la historia, (2) espacio: lo que muestra el encuadre en términos de espacio. 
La hacienda cañera aparece en Pura sangre y en Carne de tu carne, en ambas es usada para mostrar el poder económico y social. En la primera, es el espacio de la producción; en la segunda el de recreo familiar. Su papel en la cultura colombiana es mayúsculo, tal como lo expresa Germán Téllez: "La casa de hacienda neogranadina será así un gesto de desafío y posesión y una apretada madeja de ambiciones, magia e ilusión, además de la forma física que otorga validez a los recuerdos, apoyo a las costumbres y escenario al acontecer familiar" (Téllez, 1997: 32-33).

La hacienda nace en la Colonia y su etimología liga lo económico con lo espacial. El diccionario la define como "finca agrícola" y también como "cúmulo de bienes y riquezas". El énfasis en el aspecto socio-económico es el más obvio en las películas ya que la trama da cuenta de ello; desde otro punto de vista la potencia de su imagen es también aprovechada, pues la cámara presta una especial atención al registrarla como el escenario idóneo que explica con un golpe de vista toda una tradición socio-cultural. Pura sangre nos la presenta por medio de un encuadre a la altura del observador, de frente vemos una casa en forma de "L", organización espacial y tipológica para articular dos cuerpos o naves formando un patio abierto. Cada cuerpo se relaciona con el espacio por medio de un corredor. La construcción, con grandes aleros de teja deja claro su papel en la historia: el hijo del magnate sale de ella mientras lo espera su conductor.

En Carne de tu carne la hacienda es el telón de fondo para una velada descripción de la situación social y política del país en los años cincuenta. Entre puntuales referencias dialógicas a las clases sociales y al régimen político del país durante el gobierno del General Rojas Pinilla 1953-1957, poco a poco se nos descubre más su espacio, aparece el portal de entrada, límite simbólico del espacio privado en la inmensidad del valle y arquetipo de un sistema constructivo: muros de carga y cubierta a dos o cuatro aguas en teja de barro. Gran protagonismo en la puesta en escena de la hacienda, tiene el árbol frondoso que da sombra y crea un espacio de refugio en un clima tan cálido. Desde allí se vive el espacio exterior contiguo a la casa, prolongando los lugares de estar, los lugares "civilizados", donde se acomoda la mesa para que la familia meriende. Valga anotar que aunque no se ha estudiado mucho, árboles grandiosos como la ceiba o el samán han mantenido una relación espacial fundamental en la cultura vallecaucana. En la emblemática novela María (1867) de Jorge Isaacs, el frondoso árbol es testigo del amor imposible de los protagonistas y en el envés del billete de 50.000 pesos colombianos aparece en primer plano reafirmando su importancia.

\section{La ciudad}


Indudablemente el gran cronotopo en el grupo de películas es Cali, pero hay diferencias en la manera de servirse de ella, pues algunas exploran más zonas interiores y específicas de la misma. Es Pura Sangre la que se ocupa más de la ciudad como un hecho urbano total, acude a planos abiertos y elevados donde se nos muestra el perfil con sus edificios altos y las anchas avenidas. Las tomas en picado son reiteradas para situar al protagonista que desde un edificio alto domina el entorno, un entorno urbano con más edificios que casas y más vías que calles. El film, a pesar de mostrar barrios populares no ignora la imagen más cosmopolita de la ciudad, incluso introduce en la trama de manera pasajera un edificio en toda la tradición moderna de las unidades de habitación corbusianas: un gran bloque de vivienda aislado en medio del trazado urbano.

Agarrando pueblo también se ocupa de la ciudad pero su mirada es más a la altura del peatón, con cámara en mano, debido al intencional estilo documental. De hecho inicia su recorrido en la histórica Plaza de Caicedo, deteniéndose en las puertas de La Catedral de la ciudad y continúa mostrando, por medio de una panorámica, la Avenida del Río, arteria principal, los cerros que bordean Cali, algunos de sus edificios y la emblemática iglesia de La Ermita; todos ellos íconos del imaginario caleño. Tanto Agarrando pueblo como Pura sangre utilizan los recorridos en automóvil, lo cual permite una percepción del entorno diferente a los planos más estáticos.

\section{El barrio}

Localizada en inmediaciones del Barrio Obrero y San Nicolás, Aquel I9 puede considerarse la representación más íntima de un trozo de ciudad y la que se ocupa más de capturar una imagen específica. Su localización es un escenario popular tradicional con coloridas casas sin aleros. La ausencia de los aleros determina la imagen de algunos barrios populares y es una característica curiosa, ya que por tradición arquitectónica este elemento ha servido como prolongación de la cubierta de la casa con sus bondades protectoras del clima. La llegada de la arquitectura europea neoclásica adaptada en Colombia con el nombre de Republicana acogió una imagen de fachada plana con frontón, pero la referencia más directa la encontramos en el art deco y sus decoraciones geométricas. Los gestos ornamentales del ático o remate plano de la casa complementan los del zócalo, otro elemento infaltable en la parte inferior de las fachadas del barrio. Hay que añadir que toda la decoración era espontánea, lo que demuestra el gran valor que los pobladores de aquel barrio daban a la imagen de sus moradas.

El guión de Aquel Io nace paralelamente al documental Cali, cálido, calidoscopio (1985) para un concurso de mediometrajes de Focine (Compañía de Fomento 
Cinematográfico), que serían presentados por televisión. Describiendo el espíritu que envuelve el proyecto Mayolo apunta:

Cali cumplía 450 años. Ella debía construir un guión de homenaje a la ciudad, con un conocimiento de sus características. Sus arquitectos, historiadores, sus invasores de barrio, sus artistas plásticos y luego, el intangible de la ciudad, como la música, la conducta del mestizaje, la piel color de miel, el Valle del Cauca, los negros, el Pacífico, su alegría y su progreso (2008: II2).

Con todo, el tema del barrio es recurrente en las películas trabajadas, Carne de tu carne no pasa mucho tiempo en él debido a los giros del relato, pero tiene diversas escenas importantes para la definición espacio-temporal del lugar de residencia de la familia protagonista en el centro de la ciudad; además, ciertos diálogos hacen referencia a los procesos de urbanización popular de Cali en los años cincuenta. ${ }^{\circ}$ Pura sangre contrasta el estrato socioeconómico de los empleados y la familia poderosa por medio del espacio donde viven, en ese sentido, las tomas exteriores de barrios populares "explican" la división social de la ciudad. El film aprovecha los recorridos automovilísticos en busca de víctimas para también mostrar la vida de los barrios y su relación con los mitos populares. En cuanto a Rodilla negra, define su espacio más con lo idiosincrático que con lo físico. El cortometraje es un relato sobre un equipo de fútbol de un barrio muy pobre, el entorno son zonas poco consolidadas e integradas de la ciudad, dado que provienen de urbanizaciones espontáneas. La imagen del lugar subraya la pobreza y la informalidad de las construcciones y más bien documenta situaciones como el baño en el Río Pance, las pandillas, la violencia y el amor por el fútbol. Como señala Mayolo:

Es vivaz, llena de colorido y júbilo, pero no en las partes dramáticas. Yo creo que el documental se comió la ficción. Hice la cámara, la luz, el guion, la producción y la dirección [...] Faltó más guión. La música y el montaje es excelente. Era el típico cine con la firma de Caliwood: trópico, salsa y piel (2008 : 87).

\section{El patio}

El espacio interior toma una forma significativa a través del patio. Esta organización atrial tan arraigada en nuestra cultura hace su aparición, en mayor medida, cuando la trama transita hacia lo popular, con excepción de las primeras escenas de Carne de tu carne, pues se trata de la residencia de una familia adinerada. En un episodio inicial del film el espacio del comedor deja ver la relación directa que tiene con el patio, explicando un poco más la disposición atrial de la casa

Io "Yo le ayudaba a los campesinos que llegaban a Cali a hacer barrios nuevos" (Diálogo de Carne de tu carne, 39 ' 25 ”). 
y dejando testimonio de una organización espacial de las casas vallecaucanas de clase alta: el comedor mirando al patio. La retórica cinematográfica se apoya en esa casa de patio que representa una tradición arquitectónica.

El patio aparece en el inquilinato donde vive Perfecto en Carne de tu carne, incluso lo podemos ver fugazmente en Angelita y Miguel Ángel cuando Caicedo, en traje de policía, barre el pasillo, pero es en Aquel Ig donde adquiere mayor protagonismo. Es el escenario del baile del barrio, además el nudo de la historia hace uso retórico de un patio compartido para expresar la barrera que separa a los dos adolescentes enamorados. Muchas de las casas del Barrio Obrero y San Nicolás son angostas, alargadas y se organizan por pares; cada casa cuenta con un patio de iluminación que, al enfrentarse al de su casa adyacente, conforma un solo espacio vacio dividido únicamente por el muro medianero. Mayolo sitúa la cámara en un plano picado, casi cenital, de manera que en un solo encuadre vemos las dos casas: en una, el padre reprendiendo a la hija y, en el otro, el novio escuchando impotente la situación. Todo apenas separado por un muro.

\section{El arte y la transformación urbana de Cali}

Se suele señalar como el momento coyuntural en el proceso de modernización de las ciudades colombianas a los años cincuenta, la ciudad tradicional comienza a sentir modificaciones físicas, en parte, inducidas por el aumento de la pobla-

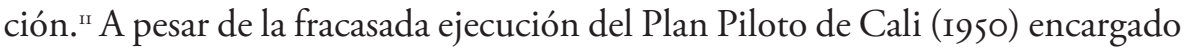
a la firma de urbanistas Wiener y Sert, dicha iniciativa representó un intento por emprender un proyecto de ciudad organizada desde la perspectiva moderna. "Atrás quedaban las intervenciones puntuales para la solución de problemas específicos de la ciudad, como el alcantarillado y la normativa de los usos del suelo requerida para el otorgamiento de las licencias de construcción" (Espinosa, 20IO: 4). El plan tenía como base los postulados del urbanismo moderno formulados por el CiAM (Congreso Internacional de Arquitectura Moderna) y de los cuales hizo parte activa Sert. Su fracaso se debe, según Espinosa, entre varios factores, a la descontextualización del proyecto respecto a las reales condiciones sociales, políticas y económicas del sector, pero también al enfrentamiento con "los intereses de los grupos terratenientes de la ciudad" (Espinosa, 20I0: 205).

El otro hecho que encarna la transformación de la ciudad en el siglo xx es la realización de los vi Juegos Panamericanos en i97I. "Nuestra ciudad era una antes de ellos, y es otra después" (Cali Panamericana, I97I: I20). Las obras metropolitanas realizadas para el evento comprenden la construcción de avenidas y

II La población municipal de Cali pasó de 87.498 habitantes en I933 a 470.000 en 1958 . La Tasa migratoria paso de I,08 en 1933 a 5,45 en I945 (Vásquez, 200I: 6) 
vías, escenarios deportivos, la Ciudad Universitaria, tres hoteles y el Aeropuerto Internacional de Palmaseca, entre otras. Los Juegos se convertirían en un hito que no pasó desapercibido para los caleńos. Para el cine tampoco, a través del documental Cali ciudad de América (1972) el cineasta Diego León Giraldo registró la versión oficial del acontecimiento. Con una mirada diferente, y de forma no-oficial, Mayolo y Ospina rodaron ¡Oiga vea! (I97I) una denuncia que con humor, pretendía mostrar la exclusión sufrida por los sectores populares de los juegos. "Por ejemplo una trampolinista se tira del trampolín, se hace un zoom-back y vemos que nadie ve la caída de la trampolinista porque la gente no ha podido entrar en el espectáculo" (Mayolo, 2008: 68).

Es indudable que el ambiente cosmopolita excitaba la ciudad de una manera nueva y propicia para que algunos artistas y creadores pusieran atención a los fenómenos urbanos, pero no siempre fue así. Como explica Osorio, "hasta hace poco el cine colombiano era casi exclusivamente rural, bien por vía del realismo mágico y folclorista, o por el reflejo de la crisis política y social del país [...]" (2005: 9). Otro tanto se puede decir de la plástica. No obstante coinciden en la década de los setenta algunos artistas que con un particular interés por lo local acompañan a Caicedo, Mayolo y Ospina en esa mirada hacia la ciudad. Su relación, además de temporal, trasciende lo casual y encuentra una resonancia cultural que en algunas ocasiones pasó a la colaboración mutua gracias al espíritu colectivo de Ciudad Solar.

El artista plástico Óscar Muñoz realiza un giro en su temática y en 1976 propicia un "encuentro con la arquitectura popular, dando comienzo a su serie Interiores. En una investigación similar estaban empeñados el fotógrafo Fernell Franco y otro dibujante, Ever Astudillo, quienes se influyeron mutuamente a nivel argumental y técnico" (González, 2007: 79). Franco retrata personajes de clases marginadas en espacios interiores, Astudillo somete

El paisaje callejero de barrios a un ambiente de bruma, con episodios donde los 'camajanes' y demás habitantes encuentran un escenario propicio en una reflexión sobre el paisaje más atmosférica que anecdótica. Muñoz se preocupó por lugares en deterioro y de tránsito congestionado. Llamó a algunas series inquilinatos, corredores, interiores, contando a nińos, ancianos, prostitutas y parejas solas en distintos momentos de intimidad [...] (González, 2007: 55-56).

\section{The End}


En primer lugar, se debe resaltar la coincidencia de una generación de artistas que miran hacia su entorno ocupándose de problemáticas más cercanas en el contexto urbano. Dentro de esa tendencia se puede detectar un interés por lo popular, tal como lo evidencia Mayolo:

Y poco a poco y a través de Ciudad Solar — una comuna que tuvimos con Luis Ospina, Andrés Caicedo, Hernando Guerrero y otros, donde hacíamos exposiciones como la de Fernell Franco sobre las putas, del pintor Óscar Muñoz. La cultura del barrio empezó a tener representatividad pictórica y fotográfica (2002: I08).

Sin embargo, esta mirada a lo local no siempre refleja el entorno natural de los artistas, dado que no todos provenían de clases populares, en ese caso se trataba más de hacer conjeturas sobre el "otro Cali". No resulta entonces casual que Astudillo, Franco y Muñoz precisamente expresaran su nostalgia por la ciudad años después en el documental de Luis Ospina Adios a Cali (1990). Hay en sus declaraciones un tono de duelo casi coral: "ya no encuentro que fotografiar", "están demoliendo todo", "ésta ya no es mi ciudad, me resisto a pasar por lugares que antes frecuentaba".

En reciente conversación con Ospina, el cineasta afirmaba que la reiteración en temas urbanos y populares del cine, la literatura y la plástica local quizá provenía de intuir que la ciudad, con los Panamericanos, se transformaba radicalmente y que aquel pueblo concentrado con límites a la vista se extendía hacia el sur, ${ }^{12}$ acentuando una linealidad inaprensible para unos jóvenes que crecieron en un territorio dividido por el río, pero que mantenía cierta centralidad. ${ }^{13}$ Observamos un apego a lo tradicional que, paradójicamente, coincide con la resistencia que mostraban por los poderes económicos respecto a los planes de modernización urbana. Los artistas se aferran a la tradición en una suerte de "realismo" que coincide con la tendencia mundial en la plástica y con el "neorrealismo y nuevo cine latinoamericano". En la plástica tiene especial relevancia una exposición: "Muñoz pudo ver en el Salón Panamericano de Artes Gráficas en Cali los dos desnudos de Darío Morales, que desde su perspectiva foto-rrealista sugestionaron a toda una generación de artistas colombianos durante esa década" (González, 2007: 79).

La resistencia y la crítica ejercida por muchos de los jóvenes creadores se enfocaron en la problemática social, al mismo tiempo los poderes económicos regulaban la modernización según conveniencia. Tal combinación se expresa a

I2 "Entre 1970 y 1993 la ciudad se expandió hacia el sur con la construcción de nuevos barrios para clases altas, medias y medias altas" (Vásquez, 200I : 294).

I3 "La década de 1970-I979 fue un periodo de creciente intervención de capital en la actividad constructora de la ciudad" (Vásquez, 200I : 293). 
través de una representación de ciudad que exalta los valores populares y tradicionales en un reflejo del apego a la tierra. Los jóvenes artistas, provenientes de familias acomodadas, retratan la tradición. El poder económico se encarga de perpetuarla.

No obstante hay que matizar tal afirmación, pues según se ha analizado, películas como Pura Sangre o Agarrando Pueblo, evitan una mirada mimética realizando la narración desde "fuera", dejando claro que en algunos casos se está retratando al "otro". En especial Pura Sangre, donde la ciudad es registrada con un enfoque más plural tal cual se expresó páginas atrás.

Capítulo aparte requiere la fallida Angelita y Miguel Ángel apenas referida anteriormente, pues permite analizar la dialéctica entre la ciudad moderna y la popular. Como primer experimento del grupo, plantea una apuesta formal muy interesante que rompe con cualquier idea realista o mimética. La adolescente que recita unos parlamentos frente a la cámara revela una puesta en escena que contradice el "montaje invisible" (término de Bazin), modo de "representación institucional" (término de Burch) donde la forma debe pasar desapercibida borrando todo rasgo enunciativo en la composición del espacio-tiempo. El film se construye sobre la tensión entre Caicedo y Mayolo, pues los intereses artísticos no coincidían del todo, de hecho fueron irreconciliables. Lo menciona Jaime Acosta en el documental que realizó Ospina con motivo de la recuperación del material filmado:

[...] ya la historia deja de referirse a Angelita y Miguel Ángel y se vuelca de una forma bastante dialéctica al universo de los dos personajes marginales. Aquí, yo creo, comienzan las divergencias entre Andrés Caicedo y Carlos Mayolo porque en el guión nunca se contempló el hecho de introducir escenas documentales.

De otro lado Angelita y Miguel Ángel, enseña fragmentos de ciudad basados en los recorridos naturales de los autores como la zona del oeste, la calle 5 y San Fernando. Algunos interiores revelan la lograda arquitectura moderna caleńa de los años cincuenta a través de una casa de formas horizontales con ventanas corridas que conforman espacios fluidos y poco cerrados, en ella Angelita baja una escalera exenta y en cantiliver. La expresión moderna de la arquitectura internacional lograda en Cali consiguió un nivel muy alto de calidad por su interpretación pertinente de los principios del Movimiento Moderno, las técnicas y el clima local. Sin embargo, es atípico para la cinematografía de Cali mostrar estos espacios, aunque en los ańos sesenta algunos realizadores europeos, refe- 
rencia obligada de los cinéfilos, situaran sus dramas existenciales en casas con características como las mencionadas. ${ }^{\mathrm{I4}}$

En el material rodado son obvios los guiños al surrealismo: la calle de un barrio residencial donde una casa moderna con cubierta plana y placa de hormigón en voladizo sobre el acceso, sirve de fondo para el paso de unas vacas. Esta imagen expresa más sobre la tensión modernidad-tradición en Cali que cualquier argumento con parlamentos explicativos. Con todo, el universo cerrado de Caicedo donde dos personajes de una clase acomodada viven recluidos en su universo y se enfrentan a un conflicto exterior, contrastó con la curiosidad de Mayolo por la "otra Cali", tal cual lo enuncia refiriéndose a Cali, cálido calidoscopio y Aquel Ig: "Era mi Cali, el barrio popular, la idiosincrasia, la búsqueda de valores primordiales que conformaban la esencia de un ente cultural que estaba desmembrado en los guiones. Se me metió un Cali inmenso en la cabeza” (Mayolo, 2008: II5).

Esta tensión se constituye en reflejo de un espejismo de modernidad, una asincronía cultural que hace coincidir el tiempo presente con un pensamiento que se aferra al pasado y en este caso a la tierra en su organización feudal. Demuestra la dificultad para enlazar tradición y futuro de manera coherente, o al menos no de forma tan traumática como la ciudad deja ver en su crecimiento. El periodo en cuestión (I97I-85) hace parte de un momento clave (como en la París de Haussmann), en que tradición y modernidad debían definir su rumbo en la estructura urbana.

Sin embargo, y como una nueva línea de investigación, sería interesante profundizar en aquella asincronía cultural antes referida, pues plantea una complejidad que se puede enmarcar dentro de lo que Martín Barbero llama "modernizaciones", es decir una visión más refinada de lo moderno: "Dos consecuencias se derivan de esa nueva visión. Una, la modernidad no es el lineal e ineluctable resultado en la cultura de la modernización socioeconómica, sino el entretejido de múltiples temporalidades y mediaciones sociales, técnicas, políticas y culturales" (Martín, Jesús, I998: 22).

Resultaría pues primordial interrogarse sobre la particular modernidad que las películas pueden plantear con su lenguaje cinematográfico, preguntarse también por la representación de modernidad o tradición de la ciudad filmada por los autores entendiendo ese "entretejido de múltiples temporalidades", ya que como jóvenes cineastas que comenzaron su trabajo en los años setenta se sitúan en una época de rupturas o mejor, en términos de Monsivais, de migraciones culturales: “desplazamientos de los hábitos, costumbres y creencias, los migrantes culturales

I4 Con énfasis en la arquitectura moderna encontramos El eclipse (I96I) y Blow Up (I966) de Antonioni; Godard con Le Mépris (1963), y Truffaut con Farenheit 45I (1966), entre otros. 
son vanguardia a su manera, que al adoptar modas y actitudes de ruptura abandonan lecturas, devociones, gustos, usos del tiempo libre, convicciones estéticas y religiosas apetencias musicales [...]" (Monsivais, $2000:$ I55-56).

\section{Referencias}

AA.vV. (2007). Paradigmas. El desarrollo de la modernidad arquitectónica visto a través de la historia del cine. La Fábrica Editorial. Madrid.

AA.vV. (2008). Los espacios de la ficción. La arquitectura en el cine. Valencia. I see books.

Arbeláez, Ramiro. (2002). "El cine en el Valle del Cauca", en: Historia de la cultura del Valle del Cauca en el siglo xx. Cali. Proartes.

Bachelard, Gaston. (2000). La poética del espacio. Buenos Aires. Fondo de Cultura Económica.

Bajtin, Mijail. (I989). Teoría y estética de la novela. Madrid. Taurus.

Barber, Stephen. (2006). Ciudades proyectadas. Cine y espacio urbano. Barcelona. Gustavo Gilli, SL.

Bordwell D., Thompson K. (2008). Film Art. New York. McGraw-Hill.

Cali Panaméricana: memoria de los vi Juegos Panamericanos de I97I. (I97I) Cali. Carvajal S.A.

Espinosa, León D. (20I0). El plan piloto de Cali. Bogotá. Universidad Nacional de Colombia.

García Roig, J. (2007). Mirada en off. Espacio y Tiempo en Cine y Arquitectura. Madrid. Mairea libros.

García Roig, J. (2008). La arquitectura del cine. Madrid. Fundación Caja de Arquitectos.

Gombrich, Ernst. (1998). Arte e ilusión. Estudio sobre la psicología de la representación pictórica. Madrid. Debate.

González, Miguel. (2007). Cali: visiones y miradas. Cali. Secretaría de Cultura y Turismo.

Gorostiza, Jorge. (2004). Cine y arquitectura. Consejería de cultura de Canarias

Hoyos, Diego León. (1994) “Agarrando el alma”. En: Revista Número, 4 Bogotá, Junio-Agosto y en Ospina, Luis. (20II). Oiga ¡vea: sonidos e imágenes de Luis Ospina. 
Mayolo, Carlos. (2008). Carlos Mayolo. La vida de mi cine y mi televisión. Bogotá. Villegas editores.

Krause, Linda. y Petro, Patrice. (2003). Global Cities: Cinema, Architecture, and Urbanism in a Digital Age. New Jersey, and London. Rutgers university press, New Brunswick.

Martín, Jesús. (1998). "Modernidades y destiempos Latinoamericanos”. En: Revista Nómadas, 8, Universidad Central, Bogotá.

Monsivais, Carlos (2000). Aires de Familia. Itinerarios convergentes y divergentes de las culturas hispanoamericanas. Barcelona, Editorial Anagrama.

Norgerg-Schulz, Christian. (1980). Genius Loci. Towards a Phenomenology of Architecture, New York. Rizzoli.

Osorio, Oswaldo. (2005). Comunicación, cine colombiano y ciudad. Medellín. Universidad Pontificia Bolivariana.

Ospina, Luis. (20II). Oiga ¡vea: sonidos e imágenes de Luis Ospina. Cali. Universidad del Valle.

Pomerance, Murray (ed.) (2007). City that never sleeps: New York and the filmic imagination, New Brunswick, New Jersey, and London Rutgers University press.

Prakash, Gyan. (20Io) Noir Urbanisms: Dystopic Images of the Modern City. Princeton University Press.

Quintana, Ángel. (2003). Fábulas de lo visible. El cine como creador de realidades. Barcelona. Acantilado.

Téllez, Germán. (I997) La casa de hacienda. Arquitectura en el campo colombiano. Bogotá. Villegas Editores.

Shiel, M. y Fitzmaurice, T. (200I). Cinema and the City: Film and Urban Societiesin a Global Context. Studies in Urbanand Social Change. Oxford. Blackwell Publishers ltd. (2003). Screening the City. Londres. Verso.

Vásquez, Edgar. (200I). Historia de Cali en el siglo 20. Sociedad, economía, cultura y espacio. Cali. Universidad del Valle.

Webber, A. y Wilson, E. (2008). Cities in Transition: The Moving Image and the Modern Metropolis. London. Wallflower Press. 